\title{
Development of a Warning System for Controlling Botrytis cinerea in Unheated Tomato Greenhouses
}

\author{
F.J. Baptista ${ }^{\mathrm{a}}$ \\ Escola de Ciências e Tecnologia \\ Universidade de Évora/ICAM \\ Departamento de Engenharia Rural \\ Núcleo da Mitra, Apartado 94, 7002-554 Évora \\ Portugal
}

J.F. Meneses

Instituto Superior de Agronomia

Universidade Técnica de Lisboa

Centro de Estudos de Engenharia Rural

Tapada da Ajuda, 1349-017 Lisboa

Portugal

Keywords: humidity, tomato

\author{
B.J. Bailey \\ Formerly at Silsoe Research Institute \\ Bedford \\ United Kingdom
}

\begin{abstract}
Botrytis cinerea is the causal agent of grey mould disease which is one of the most important diseases affecting tomato crops in unheated greenhouses. As a prophylactic measure growers usually apply large quantities of chemical fungicides for its control. Nocturnal ventilation is an effective way to reduce high relative humidity inside greenhouses and can be a useful tool to minimise chemical use in unheated greenhouses. The main purpose of this research was to develop a warning system which provides useful information about how and when to act to avoid or at least minimise disease occurrence. Experiments were carried out at the Instituto Superior de Agronomia in Lisbon in two identical adjacent double-span plastic greenhouses. Two different natural ventilation treatments were randomly assigned to the greenhouses. One was permanent ventilation (PV), with the vents open during the day and night, while the other was classical ventilation (CV), in which the vents were open during the day and closed during the night. Spring tomato crops (Lycopersicon esculentum 'Zapata') were grown directly in the soil between the end of February and the end of July for two years. Air dry and wet bulb temperatures were measured using ventilated psychrometers. All data were averaged and recorded on an hourly basis using two data logger systems. The number of leaflets with lesions caused by $B$. cinerea were counted and removed from the greenhouses from the randomly selected groups of plants. A warning system, defining disease risk levels based on disease severity was developed and can be a useful tool for technicians, advisors and growers, helping them to decide on appropriate actions and the correct timing to avoid favourable conditions for disease development. For a more practical and immediate application, disease risk levels were defined as a function of the time duration with $\mathrm{RH}>\mathbf{9 0 \%}$. This approach may help to reduce the number of chemical sprays, with unquestionable economic and environmental benefits.
\end{abstract}

\section{INTRODUCTION}

Tomato is one of the most important greenhouse crops; most of the fresh tomatoes marketed in the European Union are produced as protected crops. Greenhouse areas in the Mediterranean region have increased during the last decades, reaching 144,000 ha in 1999, with tomato being the most commonly grown vegetable (Castilla, 2002). Mediterranean greenhouses are very different from those used in northern countries. In

a fb@uevora.pt 